\title{
CUANTO MÁS GRANDE, MEJOR. [LA DIPUTACIÓN LEONESA Y LAS MANCOMUNIDADES (1914)]
}

\author{
Juan Miguel ÁlvAREZ DOMÍNGUEZ
}

\begin{abstract}
RESUMEN: El Real Decreto de Mancomunidades de 1913 abrió la posibilidad de una cierta descentralización administrativa, que únicamente fue aprovechada por Cataluña. No obstante, el tema se extendió a otros territorios. Tal es el caso de León, provincia en la que tiene lugar un debate en la prensa y las instancias políticas sobre la posibilidad de mancomunarse. Las cuestiones y particularismos que se han suscitado en León en todos los procesos de regionalización (unión a Castilla, leonesismo, afinidad con Asturias...) se ponen de manifiesto ya en 1914 en una discusión que culmina en un acuerdo de la Diputación en el que se apuesta por una mancomunidad Castellano Leonesa.
\end{abstract}

PALABRAS CLAVE: Regionalismo, Mancomunidad, León, Castilla y León.

ABSTRACT: The Royal Decree of 1913 on the establishment "Mancomunidades" (inter-provintial consortia) oponed the possibility of a certain administrative decentralisation, which was only used in Catalonia. However, this subject was debated in other territories. This was also the case in León, a province in which the press and the political establishment debated on the possibility of establishing a "Mancomunidad". The problems and specificities that have arisen in Leon in all past regionalization debates (union to Castile, Leonesism, affinity with Asturias...) were already discussed in 1914 when the "Diputación", or Provincial Council, agrees to demand the creation of a "Mancomunidad" between Castile and León.

KEYWORDS: Regionalism, “Mancomunidad”, León, Castile and León.

La aprobación del Real Decreto de 18 de diciembre de 1913, por el que se reconocía el derecho de las provincias a mancomunarse para fines exclusivamente administrativos $^{1}$, posibilitaba a las diputaciones establecer una colaboración efectiva entre varias de ellas. Esta vía indirecta de regionalización y descentralización fue utilizada únicamente por las provincias catalanas, cuya clase política había protagonizado el impulso y la presión necesarios sobre los sucesivos gobiernos centrales para que el proyecto de las Mancomunidades fuese sancionado.

1 "Real Decreto de 18 de diciembre de 1913", Gaceta de Madrid, n 353 (19 de diciembre de 1913), pp. 815-817. 
Esto ocurrió finalmente con el ministro de la Gobernación José Sánchez Guerra, miembro del gabinete conservador presidido por Eduardo Dato Iradier ${ }^{2}$. La Mancomunitat catalana se constituyó en 6 de abril de 1914, eligiéndose como presidente a Enric Prat de la Riba, y fue disuelta en 1925 por la Dictadura de Miguel Primo de Rivera ${ }^{3}$.

Aunque muy distante de la agitación vivida en el Principado, las repercusiones del Decreto también alcanzaron a otras tierras mucho menos reivindicativas de su identidad política y cultural. Tal es el caso de León. A lo que parece, y en un primer momento, los dirigentes leoneses ignoraron el asunto, como si el nuevo marco legal no les afectase, y este vacío abstencionista fue ocupado por otros actores más decididos. Un ejemplo esclarecedor de su inhibición y desinterés acontece a finales de febrero del año 1914, cuando no pudo desarrollarse una sesión extraordinaria de la Diputación leonesa requerida por el Gobernador con el motivo expreso de tratar el tema de la mancomunidad castellana, a consecuencia de invitación de la de Burgos. De los veinte diputados electos acudieron a la convocatoria nueve, con lo que no se alcanzó el quórum suficiente para poder oficiarse la reunión ${ }^{4}$. Aunque sin especificar, la cuestión se aplazó sine die.

Pero si seguimos un orden cronológico, tan al gusto de la narración histórica, habría que remontarse unos meses atrás, a diciembre de 1913, cuando al aprobarse el Real Decreto que regula la figura administrativa de la Mancomunidad, el asunto franquea los límites geográficos de Cataluña y los debates parlamentarios en Madrid.

\section{INDIFERENCIA Y ESCASO INTERÉS}

El por entonces católico y conservador «Diario de León» (la única colección integra de prensa leonesa que, abarcando la casi totalidad del siglo XX, ha sobrevivido desde su nacimiento en 1906) no dedica especial cuidado a divulgar la sanción de esta norma jurídica. La información que aporta a sus lectores se limita a escuetas notas de prensa en las que predomina un tratamiento progubernamental, basado en las notas oficiales $u$ oficiosas del ejecutivo, todas ellas redactadas por los

\footnotetext{
2 Las bases elaboradas por las diputaciones catalanas en octubre de 1911 habían sido adoptadas, con modificaciones, por el presidente José Canalejas, quien en octubre de 1912 logró el respaldo del Congreso, aunque la iniciativa legislativa se encalla en el Senado (BALCELls, A. (1999). El Nacionalismo Catalán. Madrid: Historia 16, p. 67.)

3 BalCells, A. (1999). El Nacionalismo Catalán. Madrid: Historia 16, pp. 67-68 y 87.

4 Archivo de la Diputación de León (ADL), Actas de la Diputación de León, Rollo $\mathrm{n}^{\circ} 59$. “Diligencia de sesión de 26 de febrero de 1914”, Libro 135, León, 26 de febrero de 1914.
} 
servicios de corresponsalía y agencias desde Madrid. Las reseñas de los hechos se publican en los días 17, 18 y 19 de diciembre 5 . Por lo tanto, en el caso de León, también son aplicables las apreciaciones de indiferencia y escaso interés que, según Orduña Prada y Orduña Rebollo, activa en su inicio el tema en las provincias de la actual comunidad autónoma ${ }^{6}$. Lo más destacado en estas primeras fechas es la reproducción textual en las páginas del periódico de la parte dispositiva del decreto $^{7}$, siendo remarcable la falta de artículos de opinión. Las Navidades, con su carga festiva y religiosa, terminan por ocultar la noticia.

Idéntica actitud de pasividad (ni pro, ni anti) origina la reunión que, según Almuiña Fernández, tiene lugar en Madrid a comienzos de 1914 y que pretendía vertebrar una Mancomunidad que uniría ambas Castillas, excluyendo a las provincias de León, Palencia, Salamanca, Valladolid y Zamora, por considerarlas leonesas $^{8}$. En contraste con León, ante la iniciativa madrileña, la reacción en la mayor capital de la cuenca del Duero es rápida, abogándose desde «El Norte de Castilla» por un ámbito castellano-leonés, sobre la base de la tercera y quinta regiones agronómicas ${ }^{9}$. También en aquellos primeros meses, desde Burgos se

5 ANÓNIMO. (17 de diciembre de 1913). "Las mancomunidades". En Diario de León, no 2.309, p. 3.; ANÓNIMO. (18 de diciembre de 1913). "Consejo de Ministros / Nota oficiosa". En Diario de León, n 2.310 p. 3.; ANÓNIMO. (19 de diciembre de 1913). "En Gobernación". En Diario de León, $\mathrm{n}^{\circ} 2.311$, p. 3.; y ANÓNIMO. (19 de diciembre de 1913). "En torno a un Decreto". En Diario de León, no 2.311, p. 3.

${ }^{6}$ ORDuÑA, M. (2004). "Las diputaciones de Castilla y León y el regionalismo". Regionalismo y autonomía en Castilla y León. Valladolid: Junta de Castilla y León, p. 96. y ORDUÑA, E. (1986). El regionalismo en Castilla y León. Valladolid: Ediciones Ámbito, p. 123.

${ }^{7}$ ANÓNIMO. (20 de diciembre de 1913). "Las Mancomunidades. Decreto". En Diario de León, $\mathrm{n}^{\mathrm{o}}$ 2.312, p. 2.

${ }^{8}$ AlmuiÑA, C. (1984). "El regionalismo castellano-leonés: orígenes y primeras reivindicaciones político-económicas (1859-1923)”. En I Congreso de Historia de Castilla y León. Vol. III. Burgos: Junta de Castilla y León, p. 356.

${ }^{9}$ ORDUÑA, E. (1986). El regionalismo en Castilla y León. Valladolid: Ediciones Ámbito, p. 125; y ORduÑA, M. (2004). "Las diputaciones de Castilla y León y el regionalismo". Regionalismo y autonomía en Castilla y León. Valladolid: Junta de Castilla y León, pp. 96-97. Estas regiones agronómicas se crean por el Real Decreto de 10 de octubre de 1903, que establece una parcelación en 13 demarcaciones. Entre ellas estaban las denominadas Castilla la Vieja (con capital en Valladolid) y León (con capitalidad en Zamora). Esta norma legislativa no concreta la composición provincial de cada región, por lo que es complementada días más tarde, en 14 de octubre, con una Real orden en la que se produce la aclaración. Este último texto notifica que Castilla la Vieja estaba conformada por las provincias de Valladolid, Segovia, Burgos, Ávila y Soria; y León por Zamora, León, Salamanca y Palencia. ["Gaceta de Madrid", n 284 (11 de octubre de 1903), pp. 137-139; y "Gaceta de Madrid", $\mathrm{n}^{\circ} 290$ (17 de octubre de 1903), p. 225.] A posteriori debieron de producirse cambios, pues la actual 
planifican encuentros conducentes a poner en marcha distintos proyectos de mancomunidad, y desde Segovia se labora por la separación entre leoneses y castellanoviejos $^{10}$.

Como en otras ocasiones, precedentes y futuras, se podría afirmar que León sesteaba. Evidente prueba de ello fue la frustrada sesión extraordinaria de la diputación en febrero de 1914, ya comentada anteriormente.

La aprobación de la Mancomunitat a principios de abril tampoco provoca reacciones en la urbe legionense, y su nacimiento es recibido el día 4 con un prematuro breve: Dicen de Barcelona que reunidos los presidentes de las Diputaciones provinciales Catalanas, han acordado el orden del día para la discusión de la Asamblea de constitución de las Mancomunidades catalanas ${ }^{11}$. En las semanas posteriores, las distintas noticias que llegan de la Ciudad Condal tendrán como principal protagonista la agitación obrera y sindical, hallándose, ya en 23 de junio, una reseña de esta institución, inocua desde todo punto de vista ideológico. Al parecer, este organismo se había comprometido a liquidar una deuda de las diputaciones de Lérida y Tarragona ${ }^{12}$.

\section{CON EL ESTÍO LLEGÓ LA ACCIÓN}

Será ya con los aires veraniegos cuando el segundo y cuarto poderes leoneses (ejecutivo y prensa), los políticos con una cita pendiente en Burgos como espada de Damocles sobre su responsabilidad, asumen parte de sus compromisos y comienzan a actuar.

comunidad autónoma de Cantabria, que en un origen estaba en la región denominada Asturias y Provincias Vascongadas (ostentando Santander su capitalidad) pasó a estar integrada en la de León. Así se desprende de la nota a pie de página $n^{\circ} 347$ del libro: PAlomares, J. M. (1981). Valladolid, 1900-1931. Valladolid: Ateneo de Valladolid, p. 100. Pero las modificaciones tuvieron que producirse ya al poco tiempo de promulgada la misma normativa, pues en un artículo firmado por Quintiliano Saldaña en septiembre de 1906 puede leerse la frase: La región leonesa, a los efectos de la distribución oficial de la península en zonas o regiones agrícolas (...) se compone de las provincias siguientes: Salamanca, Zamora, Santander, Palencia y León. [SALdAÑA, Q. (18 de septiembre de 1906) "La Granja Instituto de la región leonesa". En Diario de León, no 186, p. 1.]

${ }^{10}$ Almuiña, C. (1984). "El regionalismo castellano-leonés: orígenes y primeras reivindicaciones político-económicas (1859-1923)”. En I Congreso de Historia de Castilla y León. Vol. III. Burgos: Junta de Castilla y León, p. 356.

${ }^{11}$ AnÓNimo. (4 de abril de 1914). "Las Mancomunidades”. En Diario de León, no 2.398, p. 3.

12 ANónimo. (23 de junio de 1914). "La mancomunidad catalana". En Diario de León, no 2.403, p. 1. 
Todo indica que los primeros en hacerlo son los parlamentarios por la provincia, que tienen una reunión en Madrid el 17 o 18 de junio para tratar de la constitución de las Mancomunidades. Según revela el rotativo católico, convinieron asistir a la Asamblea de las Diputaciones castellanas que se iba a celebrar en la ciudad burgalesa ${ }^{13}$.

También en la Villa y Corte, y afectando a un marco geográfico más extenso, aconteció una segunda cita entre los días 18 y 19 del mismo mes. A la Sección segunda del Congreso acudieron varios electos de la Cámara Baja por las provincias de Castilla la Vieja y León. El propósito de la convocatoria fue tratar del proyecto de Mancomunidad Castellana que será objeto de una reunión de las Diputaciones de las citadas regiones el día 20 en Burgos. El redactor identifica, por lo general mediante los apellidos, a los siguientes hombres ${ }^{14}$ :

Abilio Calderón: Abilio Calderón Rojo (Grijota, 1867-Palencia, 1939) Abogado, elegido por la circunscripción y distrito de Palencia; pertenecía a la fracción política conservadora.

Zorita: José María Zorita Díez (Tordesillas, 1859-Valladolid, 1942) Abogado y diputado por la circunscripción de Valladolid y distrito de Nava del Rey. Se le adscribe al liberalismo.

Galarza: Ángel Galarza y Vidal (Zamora, 1856) Militar, representaba a la circunscripción y distrito de Zamora. Como el anterior, se le encuadra dentro de los liberales.

Oliva: Isidro Pérez Oliva (Salamanca, 1864-¿?, 1929) Abogado del Estado y diputado por la circunscripción y distrito de la capital salmantina. De ideología liberal.

Ruano: Juan José Ruano de la Sota (Santander, 1871 - Madrid, 1930) Letrado, votado por la circunscripción y distrito de Santander. Se le adscribe a la fracción conservadora ${ }^{15}$.

13 ANÓNIMO. (19 de junio de 1914). “Los diputados por León”. En Diario de León, nº 2.459, p. 3.

14 Todas las identificaciones, así como lo relativo al nacimiento y muerte, profesión, fracción política y geografia electoral (distrito y circunscripción) se han recogido de un banco de datos al que se accede a través de la página web del Congreso de los Diputados (www.congreso.es). La única excepción ha sido Gumersindo de Azcárate, cuya reseña se ha enriquecido con otras fuentes.

${ }^{15}$ En el Cámara Baja había otro diputado que respondía al nombre de Fernando Ruano Prieto, pero queda descartado, pues era representante de Teruel. 
Muñoz: este apellido presenta dos posibles candidatos. Prudencio Muñoz y Álvarez (Madrid, 1880) Abogado y liberal electo por la circunscripción y distrito de Logroño; o Julián Muñoz y Miguel, de idéntica profesión y credo político, elegido diputado por la circunscripción de Soria y distrito de El Burgo de Osma.

Zarandona: Francisco Zarandona Valentín (Valladolid, 1868-1915) Abogado conservador, salió favorecido por la circunscripción de Zamora, distrito de Villalpando.

Arias Miranda: Santos Arias de Miranda y Berdugo (Aranda de Duero, 1879) Parlamentario por su provincia natal y distrito de Aranda de Duero. Estaba adscrito a la fracción liberal, $\mathrm{y}$, al igual que muchos de los anteriores, también tenía como profesión la abogacía.

Azcárate: Gumersindo de Azcárate y Menéndez (León, 1840-Madrid, 1917) Seguramente el personaje más renombrado de una de las sagas familiares más influyentes y activas de la política leonesa de los siglos XIX y XX. Diputado por la circunscripción y distrito de León, era un reputado catedrático vinculado al republicanismo y a los postulados de la Institución Libre de Enseñanza.

Aparicio: Francisco Aparicio y Ruiz (Burgos, 1852) Parlamentario por la circunscripción y distrito de Burgos. Era un abogado de ideología conservadora.

El periodista también nombra a un tal Dueñas, pero no aparece como apellido de ningún congresista castellano o leonés elegido en aquel periodo electoral.

La nota informativa ${ }^{16}$ es parca en los contenidos y conclusiones. En ella se apunta que fue Calderón Rojo quien expresó el objeto de la reunión, y que José María Zorita dijo que por este proyecto no siente ni grandes entusiasmos ni grandes odios, y que lo único que hay que examinar es que si las provincias castellanas por sus propios medios y por los recursos que el Estado pueda proporcionarlas podrán cumplir con los compromisos que la Mancomunidad las ha de imponer. Además, auguró que no creía que se hubieran de presentar ni grandes obstáculos, ni tampoco se mostrarán grandes optimismos. El resumen corrió por cuenta del leonés Gumersindo de Azcárate, quien desarrolló atinadas observaciones sobre la extensión que debe darse a la mancomunidad, manifestando que era preciso que se tengan en cuenta las iniciativas de Castilla,

16 ANÓNIMO. (20 de junio de 1914). "Reunión de representantes castellanos". En Diario de León, $\mathrm{n}^{\circ} 2.460$, p. 2 . 
tan abandonada en sus pretensiones por los Poderes públicos. El encargado de entregar al Gobierno la nota con los acuerdos tomados fue Francisco Aparicio.

Por una información del servicio telegráfico que se publica en Diario, se comunica a la opinión pública leonesa en 23 de junio lo concertado en Burgos por los representantes de las diputaciones allí congregados. Textualmente se afirma como principal resolución que se aceptó la idea de la mancomunidad que desarrolla el R. D. de 18 de diciembre de 1913 y se acordó la ...veniencia ${ }^{17}$ de llevarla a la práctica bajo la denominación de Mancomunidad Castellana ${ }^{18}$. De la noticia, también se desprende que no concurrieron delegados provinciales de Ávila, León, Logroño y Zamora.

Será ya a finales de junio cuando el tema llegue al interfluvio Bernesga-Torío, logrando un cierto protagonismo con varios debates en la Diputación y escritos de opinión en los periódicos. Lo cierto era que las fuerzas vivas de León reaccionaban con medio año de retraso respecto a las de otros territorios.

\section{LA DISCUSIÓN EN LA PRENSA: «DIARIO DE LEÓN»}

Se desarrolla durante todo el mes de julio, y son tres personas las que intervendrán con opiniones y argumentos diversos. Dos de ellos con un único artículo (Nodrab y Clemente Vilorio) y un tercero con una serie de cinco (G.).

El primero en salir al ruedo mediático fue Nodrab en 1 de julio ${ }^{19}$. Comienza manifestando que ante los próximos plenos de la Diputación en los que se ha de tratar la actitud de la provincia de León ante la Mancomunidad, sería útil que la opinión se manifestase de algún modo, para que nuestros diputados se orientasen antes de resolver tan vital problema. Además, las opiniones emitidas por los que quieran colaborar en la prensa, o por cualquier otro medio harán luz y servirán de punto de donde haya de partir la discusión. Lo que el articulista mantiene que debe decidirse en primera instancia es saber si a León le conviene entrar en mancomunidad. $\mathrm{Y}$ en el caso de que esa respuesta sea afirmativa propone que se estudie detenidamente con que provincias convendría asociarse. Para la elección aconseja que es preciso discurrir sin prejuicios ni apasionamientos, atendiéndose solamente al interés con que hayamos de beneficiarnos; y advierte del riego de

\footnotetext{
${ }^{17}$ El inicio de esta palabra resulta ilegible, pero seguramente corresponda a conveniencia.

18 ANÓNImo. (23 de junio de 1914). "La Mancomunidad Castellana". En Diario de León, n

19 Nodrab. (1 de julio de 1914). "Las mancomunidades". En Diario de León, $\mathrm{n}^{\mathrm{o}} 2.468$, p. 1. (Nodrab corresponde al apellido Bardón leído de derecha a izquierda)
} 2.462, p. 3 . 
caer en las redes de otra nueva centralización, que además de sernos perjudicial, nos sería onerosa, porque tendríamos que pagar la parte proporcional de los gastos. Nodrab señala que tal vez nos convenga entrar en una mancomunidad en la que ingrese Asturias, puesto que es la provincia con la que tenemos más relaciones mercantiles, y es la que más productos consume de los que vendemos. Tenemos intereses y aspiraciones que nos son comunes, y en nada antagónicas. Ambas provincias necesitan ferrocarriles que las unan y que atraviesen sus cuencas mineras.

A mediados de ese mismo mes, y con el título unitario de León y las Mancomunidades, un autor que escondía su identidad tras la letra $G$ redacta un conjunto de escritos sobre lo que él considera debiera ser el modo de actuar de los dirigentes leoneses ante esta cuestión. El opinante se muestra contrario a que la provincia se mancomune, aduciendo como argumentaciones principales las cuatro siguientes $^{20}$ :

$1^{\text {a }}$. Falta de demanda en la sociedad, tanto de las élites como del pueblo llano.

$2^{\text {a }}$. Hipotética traición a la misma historia regional por el peligro que en la parcelación pudiera existir para la unidad española ${ }^{21}$.

$3^{\text {a }}$. La propia diversidad provincial haría difícil integrarla en un ente que satisficiese a todas las partes.

Y 4 a ,, escasez de recursos internos para asumir los gastos que deviniesen.

En el mismo número en que G. finaliza sus cinco artículos, irrumpe Vilorio de Altobar con un texto ${ }^{22}$ en el que discrepa de la propuesta de Mancomunidad Castellana. Sin ambages ni subterfugios y destilando en cada frase una vindicación ideológica de leonesismo, reclama la no adhesión, pues hasta por el nombre de simplemente "castellana" parece debía rehusar León semejante Mancomunidad. El órdago regionalista (o nacionalista) es claro, y se refuerza con la apuesta por la restauración de los Fueros y Privilegios... debidamente adoptados, lo que presenta un cariz político y reivindicativo que, incluso, estaba mucho más allá de la letra del

${ }^{20}$ G. (13, 16, 17, 18 y 21 de julio de 1914). "León y las Mancomunidades”. En Diario de León, p. 1, p. 1, p. 2, p. 1, y p. 1 .

${ }^{21}$ La supuesta traición histórica se asienta en la idea (muy extendida) de que León hizo España, y que por lo tanto, jamás debería adherirse a un proyecto que pudiese contribuir a su disgregación política.

${ }^{22}$ Vilorio, C. (21 de julio de 1914). “Carta abierta”. En Diario de León, nº 2.485, p. 1. 
Real Decreto. Su propuesta, más laudable y de resultados más prácticos y beneficiosos sería una Mancomunidad exclusivamente leonesa, formada por las provincias que fueron y las que, geográficamente al menos, siguen siendo de León. Pero Vilorio se muestra más ambicioso, y no duda en proponer como solución más verdadera y decorosa: una Federación de las Regiones que pertenecieron a los Monarcas leoneses. El marco geográfico propuesto para tal Federación abarcaría Galicia, Asturias, León (no especifica con qué territorios limitaría por oriente) y Extremadura, con lo que estaríamos ante uno de los escasos planteamientos panleonesistas de la historia contemporánea. El autor, con pragmatismo, no deja de contemplar esta posibilidad como utópica, dadas la poca preparación que se advierte para ello y la ninguna conciencia que de sí tienen, no sólo los asturianos, gallegos y extremeños, sino también y principalmente nosotros los leoneses, llamados por la Historia, situación y carácter a iniciar obra tan consoladora y trascendental para todos.

Así mismo, el Diario informa puntualmente a sus lectores de lo acontecido en los debates que sobre la cuestión de la Mancomunidad tuvieron como escenario el Palacio de los Guzmanes, sede de la Diputación ${ }^{23}$.

\section{LAS SESIONES DE LA DIPUTACIÓN LEONESA}

Tras la fallida de 26 de febrero, habrá que esperar cuatro meses y a la apertura de un nuevo periodo de reuniones. La Mancomunidad fue el principal tema de tres plenos que transcurrieron en los días 26 de junio, y 1 y 13 de julio ${ }^{24}$. Según las actas, intervinieron en los debates un total de 8 de los 20 diputados que componían el organismo. El nombre completo, fracción política, y distrito electoral por el que resultaron electos son los siguientes ${ }^{25}$ :

José Eguiagaray Mallo (Liberal - Distrito de León-Murias de Paredes)

Mariano Alonso Vázquez (Liberal - Distrito de Sahagún-Valencia de don Juan)

23 ANÓNIMO. (27 de junio de 1914). "En la Diputación”. En Diario de León, no 2.466, p. 2.; ANÓNIMO. (2 de julio de 1914). "En la Diputación”. En Diario de León, no 2.469, p. 2.; ANÓNIMO. (13 de julio de 1914). "A la Asamblea". En Diario de León, no 2.478 p. 2.; ANónIMo. (14 de julio de 1914). “En la Diputación”. En Diario de León, no 2.479, p. 2.

${ }^{24}$ En 27 de junio se trasladó el acuerdo a la siguiente.

${ }^{25}$ Los datos personales y políticos han sido tomados de: CARAntoña F. y PUEnTE G. (1995). Historia de la Diputación de León. León: Instituto Leonés de Cultura, p. 629. 
Alfredo Barthe Sánchez-Sierra ${ }^{26}$ (Liberal - Distrito de Riaño-La Vecilla)

Isaac Balbuena Iriarte (Conservador - Distrito de León-Murias de Paredes)

Félix Argüello Vigil (Liberal - Distrito de Riaño-La Vecilla)

Mariano Domínguez Berrueta (Conservador - Distrito de Astorga-La Bañeza)

Germán Gullón Núñez (Liberal - Distrito de Astorga-La Bañeza)

Isaac Alonso González (Conservador - Distrito de Ponferrada-Villafranca del Bierzo)

Pleno de 26 junio $^{27}$

La materia surge por una consulta que formula el diputado José Eguiagaray a la presidencia. Eguiagaray pregunta si se habia adoptado algún acuerdo o resolución respecto a la mancomunidad de las provincias castellanas, asunto que estimaba de gran importancia, y por lo mismo entendia que debía nombrarse una Comisión permanente que lo estudiara con el detenimiento necesario y propusiera a la Asamblea lo que estimara procedente sobre la conveniencia de formar o no parte de la mancomunidad.

En la respuesta del presidente, Mariano Alonso Vázquez, se advierte que si no concurrieron representantes de la institución a Burgos fue debido a que no se había tenido noticia oficial de dicho encuentro. Empero, a continuación, ordenó que se diese lectura de los antecedentes y acuerdos adoptados en la ciudad castellana. Alonso Vázquez concluye mostrándose conforme con la idea de Eguiagaray de nombrar una comisión, para que en la sesión de mañana dictaminase, toda vez que el asunto es de gran importancia ${ }^{28}$.

Eguiagaray protesta por la cortedad del plazo que la presidencia concede a la delegación y Alonso responde que por ahora no se trataba de formar la

${ }^{26}$ El segundo apellido está tomado de la propia esquela del político: "Esquela de Alfredo Barthe Sánchez-Sierra". En Diario de León, n 6.727, (2 de marzo de 1923), p. 2.

27 ADL, Actas de la Diputación de León, Rollo n 59. "Acta de la sesión de 26 de junio de 1914", Libro 135, León, 26 de junio de 1914.

${ }^{28}$ Sorprende la premura con la que el presidente quiere solucionar la cuestión, conformando una delegación a la que se le obliga a estudiar y decidir en menos de veinticuatro horas. Alonso Vázquez justifica esta celeridad porque los Sres. Diputados (...) tendrá formado perfecto juicio de lo más conveniente a los intereses de esta provincia. 
mancomunidad, sino de una reunión de delegados de las Diputaciones para estudiar si convenía o no llegar a establecerla.

A continuación se unieron al debate otros políticos de la provincia.

Alfredo Barthe mantuvo que era necesario establecer las bases con las que la provincia iría en Mancomunidad, y que si estos presupuestos eran rechazados por otras provincias, él se opondría al proyecto.

Eguiagaray se mostró conforme.

Isaac Balbuena se postuló hostil a la unión con la Mancomunidad Castellana, arguyendo que esta provincia tenía intereses encontrados con algunas de las que van a constituir aquélla, como sucede en la actualidad con la construcción del ferrocarril de Valladolid a Vigo, y opina que hay más en común con las de Oviedo y Santander y acaso con la de Lugo.

Félix Argüello convergió con Eguiagaray en la necesidad de la comisión y en que el lapso de tiempo que se le procuraba para deliberar era escaso. Así mismo, y sin que se sienta preferencias por unas u otras provincias, (...) deben ser cuantas más mejor y formarla grande, para contrarrestar las exigencias de otra ya constituida y evitar que nos arrollen. Aseguró que Asturias había dado pruebas recientemente de que nos recibiría con los brazos abiertos.

Balbuena indicó su conformidad con una parte de esta última intervención, y rectificó su parecer, planteando que se debe ir a la mancomunidad para resistir el empuje de Cataluña, cuyo espíritu ha sido siempre regional, espíritu que, aseveró, faltaba en León.

Mariano Domínguez apoyó ir con las más y las mejores.

Germán Gullón dijo que él era opuesto a las mancomunidades porque éstas pueden ser el principio de la desintegración de la patria y considerándolas económicamente han de traer la ruina a la provincia.

Barthe indicó que debía irse en alianza con las que forman región para la elección de un Senador por las Sociedades Económicas ${ }^{29}$.

29 Según la Ley de 8 de febrero de 1877, Las Sociedades Económicas de Amigos del País (...) designarán un Senador por cada una de las regiones que a continuación se establecen (...) A los de León, los de Rivadeo, Liébana, Oviedo, Palencia, Santander, Santiago y Zamora. Además de la urbe legionense, se establecían otras cuatro capitales de región: Madrid, Barcelona, Sevilla y Valencia (Esta normativa se publica en: “Gaceta de Madrid", nº 41 (10 de febrero de 1877), pp. 373-375.) 
Tras el plural intercambio de pensamientos, retomó al uso de la palabra quien lo inició, Eguiagaray. Sostuvo que la fuerza de Cataluña no está en la mancomunidad sino en el amor de los catalanes a su tierra ..pecto de lo cual no piden a los Poderes públicos sino que se imponen, que si nosotros conseguimos representantes que tengan ese amor a la tierra leonesa, tendremos también fuerza y para ello debemos estar al lado de los que lo demuestren con sus actos y desechar a los indiferentes.

Cerró el turno de participaciones Isaac Alonso, quien insistió en la sugerencia de crear la Comisión, de la que tendría que ser miembro el Sr. Presidente.

Acto seguido quedó designada, siendo elegidos Mariano Alonso y los Sres. Argüello, Alonso (D. Isaac), Eguiagaray, y Domínguez Berrueta.

Si se ha optado por reproducir todas las intervenciones del debate originado en esta primera sesión es porque en él se advierten ya una serie de ideas y temáticas, en no pocas ocasiones opuestas, que marcaron la actitud y el enfoque de las autoridades políticas leonesas ante los diferentes procesos de regionalización (desde los que tienen lugar en los años veinte-treinta hasta los de los setentaochenta de la pasada centuria). Sucintamente se compendian en los siguientes cinco puntos:

$1^{\circ}$. El temor a formar parte de un proceso que potencialmente podría coadyuvar a la desmembración de España (Gullón).

$2^{\circ}$. Intereses enfrentados con otras provincias durienses (Balbuena).

$3^{\circ}$. Afinidad con Asturias (Argüello) o con otros territorios limítrofes ajenos a Castilla (Balbuena), y por lo tanto una ambigüedad en el marco geográfico al que se aspiraba, que en ocasiones se trasluce en cambio de pareceres y adaptabilidad a las circunstancias.

$4^{\circ}$. Recelo hacia Cataluña (y por extensión a otros territorios peninsulares donde el nacionalismo era pujante), ante la que hay que defenderse apostando por una gran coalición (Argüello y Balbuena). Esto se relaciona estrechamente con el primero de los puntos expuestos.

$5^{\circ}$. Un anhelo ambiguo por desarrollar un cierto «regionalismo leonesista». Fácilmente deducible de la última reflexión de Eguiagaray cuando aboga por representantes que tengan (como los catalanes hacia Cataluña) ese amor a la tierra leonesa.

Estas características serán también observables en las sesiones sucesivas. 
Pleno de 27 de junio ${ }^{30}$

Alfredo Barthe pregunta a la presidencia sobre la Comisión que se había nombrado para tratar sobre las mancomunidades, asunto que no debe dejarse sin resolver. Gullón contestó que sería conveniente posponerlo hasta el miércoles, ya que sino faltarían varios diputados. Se accedió a obrar de acuerdo a lo sugerido por Germán Gullón.

\section{Pleno de 1 de julio ${ }^{31}$}

El encargado de presentar ante la asamblea el dictamen de la Comisión es Félix Argüello, quien explica que inicialmente se debatió sobre si la provincia debía o no mancomunarse. Razona que se inclinaron por la opción afirmativa debido a que hace tiempo que las Diputaciones se vienen reuniendo y nombrado delegados, en cuanto sentían la necesidad de reclamar al Gobierno reformas, modificaciones, servicios, y mejoras. Continuó argumentando que de aquellas reuniones nació la Liga de Diputaciones Castellanas y que, tras la nueva disposición legislativa de 18 de diciembre de 1913, la necesidad se siente hoy más, después de constituida la catalana. Por todo ello convinieron la necesidad de la mancomunidad de la provincia de León que además de todo lo dicho la abona las razones históricas en cuanto León y Castilla se unieron sólo por defender la unión nacional.

En lo que concierne a las circunscripciones con las que mancomunarse, se optó por el planteamiento ya esbozado por algunos diputados en la sesión anterior, conviniéndose que sea con el mayor número posible para que resultara de más fuerza y más barata. En lo referente a la identidad de dichas provincias se miró hacia Asturias, pero a pesar de los muchos puntos comunes se alegó que la aduana perjudicaba a los productos leoneses, además de que resultaría muy pequeña con ese sólo reino, no quedando más que la mancomunidad castellana, la que se exigirá sea llamada Castellana Leonesa y de no poderse formar con toda Castilla unirse a las provincias que en mayor número hayan pertenecido al reino de León.

Finalmente, y en lo que se refiere a las condiciones de adhesión, se opta por el legalismo de lo expuesto en el Real Decreto, resumido por Argüello en que el nuevo ente habría de promover o fomentar los intereses morales y materiales, ejecutar servicios que la ley encomienda a las Diputaciones que afecten a dos o

30 ADL, Actas de la Diputación de León, Rollo n ${ }^{\circ}$ 59. "Acta de la sesión de 27 de junio de 1914", Libro 135, León, 27 de junio de 1914.

${ }^{31}$ ADL, Actas de la Diputación de León, Rollo n 59. "Acta de la sesión de 1 de julio de 1914", Libro 135, León, 1 de julio de 1914. 
más provincias, recabar del Estado los servicios que hoy tienen centralizados y que pueda desempeñar la mancomunidad, en una palabra, restableciendo en toda su pureza la Ley de provincias y dando la mayor autonomía a estas Corporaciones.

Balbuena solicita intervenir, y acusa a la comisión de no haber cumplido diligentemente con su encargo, y por lo tanto, pide que vuelva a estudiarse.

Gullón, que sigue mostrándose contrario, inquiere por la capitalidad del futuro organismo y por los recursos económicos con los que habría de contribuir la provincia.

Eguiagaray, como vocal comisionado, contesta a las objeciones de Balbuena y atribuye la no elaboración de un dictamen más competente a la falta de tiempo, defendiendo la labor de los miembros de la comisión.

Argüello replica a Gullón que hasta conocer la composición provincial definitiva no se puede resolver la cuestión de la capital, pero que la historia no transcurre en valde (sic) y a la influencia de León se fue sobreponiendo la de Castilla, con lo que hoy sólo nos contentaremos con que se llame Castellano Leonesa. En lo referente a los recursos económicos, supone que se habrá de contribuir con muy poco.

Ante esto, Gullón objetó que los prestigios antiguos de León no deben olvidarse y se debe aspirar por lo menos que la capitalidad sea cada año en una provincia distinta.

El último en intervenir fue Barthe, que se opuso a las mancomunidades, aunque no habrá más remedio que recoger los derechos que nos dan.

Debido a la falta de quórum la sesión tuvo que levantarse sin la votación necesaria, con lo que todo quedó en suspenso hasta la siguiente.

Aunque el acta no advierte nada, en la información que ofrece el Diario, se relata que, tras acalorada discusión, Isaac Balbuena abandona el salón por creerse desamparado en sus derechos ${ }^{32}$.

32 ANÓNIMO. (2 de julio de 1914). “En la Diputación”. En Diario de León, no 2.469, p. 2. 


\section{Pleno de 13 de julio ${ }^{33}$}

Todo parecía indicar que el debate ya estaba finiquitado, pero éste se reanudó con el mismo diputado que había sido el último en intervenir. Alfredo Barthe comunicó que lo que se debía solicitar del Estado era la extinción de las Audiencias Territoriales, pasando sus competencias a las de las provincias, y que con esta pretensión se recabaría el apoyo de todas las provincias castellanas con las excepciones de Valladolid y Burgos. También que las oposiciones se descentralizasen de Madrid, y por último que se solicitara para la mancomunidad castellana todo lo que se le hubiese concedido a la de Cataluña.

Germán Gullón señaló que únicamente se estaba hablando de las ventajas, y vaticinó que se apuntaban en el horizonte perjuicios como la guerra civil entre las provincias, y que la cuestión económica no estaba bien aclarada, y puesto que la Diputación leonesa carecía de rentas y sobrantes en sus presupuestos, tendría que acudir al aumento de contingentes, lo que damnificaría a sus habitantes.

Félix Argüello formula un discurso sobre la conveniencia de ir a la mancomunidad porque la centralización ha llegado a su más alto grado, y las provincias mueren faltas de vida y de recursos y el único medio de salir de ese estado será la mancomunidad. En lo referente a la carga extra sobre las arcas provinciales, manifiesta que aunque la creación de este organismo sea costosa[,] cuando entren a formarla el mayor número de provincias posible el capital a desembolsar por las prestaciones facilitadas será muy semejante al actual.

Gullón no queda muy convencido y mantiene su idea de una capitalidad rotatoria entre las provincias.

Mariano Domínguez opina que el Real Decreto gubernamental tiende a crear el regionalismo y en vista de que Castilla no tiene espiritu de asociación sería conveniente ir a la mancomunidad para este fin. Y en relación a los recursos mantiene que la situación es análoga en todas las provincias castellanas, muchas de ellas en condiciones iguales a la nuestra, de forma que (lo que) ellas ofrezcan, ofrecerá esta Diputación. Y que las ventajas se cifrarían en los servicios que cede el Estado y en poder administrar los intereses provinciales.

El acta recoge (sin especificar en qué consistieron) las rectificaciones de los diputados Gullón y Argüello, la conformidad con el tema de Francisco Sanz, y

33 ADL, Actas de la Diputación de León, Rollo n 59. "Acta de la sesión de 13 de julio de 1914”, Libro 135, León, 13 de julio de 1914. 
concluye con la enumeración de los cuatro puntos acordados en la subsiguiente votación:

$1^{\circ}$. La mancomunidad con el mayor número de provincias castellanas, procurando se denomine de Castilla y León: $2^{\circ}$. Que las Juntas generales se celebren cada año en una de las provincias mancomunadas: $3^{\circ}$. Que la Comisión o Consejo permanente tengan representación en él las provincias de mayor número de habitantes, y $4^{\circ}$. Nombrar representantes de esta Diputación a los Sres. Argüello, Gullón, Dominguez Berrueta y Presidente

Con este voto se dio por concluido en el organismo provincial leonés el debate sobre las Mancomunidades y el propio periodo semestral de reuniones. El acuerdo, claro y conciso en sus conclusiones, se convirtió, a tenor de lo que aconteció en los años ulteriores, en papel mojado, pues como afirma Palomares Ibáñez al respecto de la mancomunidad: Cataluña subió al tren. Castilla y León no ${ }^{34}$; y eso, a pesar de que el organismo provincial leonés compró billete de ida.

34 Palomares J. M. (1990). “Crecimiento económico, tensiones sociales, y fase inicial del movimiento regionalista en Castilla y León en los comienzos del siglo XX". En Las Cortes de Castilla y León, 1188-1998: actas de la Tercera Etapa del Congreso Científico sobre la historia de las Cortes de Castilla y León. Vol. II. Fuensaldaña: Cortes de Castilla y León, p. 290. 


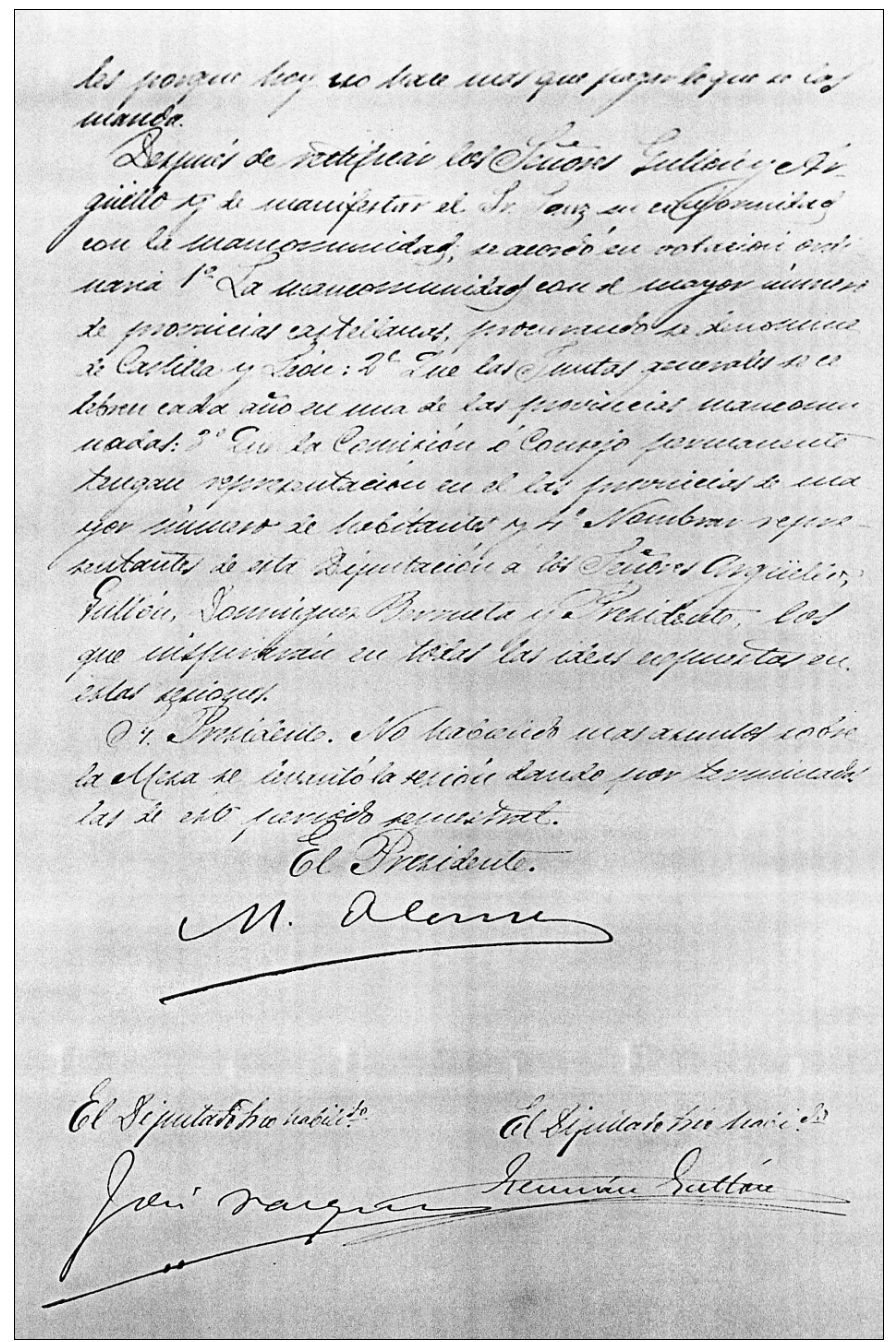

Reproducción de la página correspondiente al acuerdo de la Diputación por el que se vota a favor de la creación de una Mancomunidad de Castilla y León (ADL, Actas de la Diputación de León, Rollo $n^{\circ}$ 59. "Acta de la sesión de 13 de julio de 1914”, Libro 135, León, 13 de julio de 1914.) 